\title{
Ocean state indicators from MyOcean altimeter products
}

\author{
L. Bessières ${ }^{1}$, M. H. Rio ${ }^{2}$, C. Dufau ${ }^{2}$, C. Boone ${ }^{2}$, and M. I. Pujol ${ }^{2}$ \\ ${ }^{1} \mathrm{AS}+$ EOLEN, 5 avenue Didier Daurat, 31400 Toulouse, France \\ ${ }^{2}$ CLS-DOS, 8-10 rue Hermès - Parc Technologique du canal, 31250 Ramonville Saint Agne, France \\ Correspondence to: L. Bessières (laurent.bessieres@cls.fr)
}

Received: 1 March 2012 - Published in Ocean Sci. Discuss.: 24 May 2012

Revised: 17 April 2013 - Accepted: 26 April 2013 - Published: 12 June 2013

\begin{abstract}
The European MyOcean project (http://www. myocean.eu.org) provides observations of the ocean dynamic topography from altimeter measurements. Three specific indicators have been developed, based on altimeter data only, in order to monitor the ocean state. The first ocean indicator observes the positive and negative phases of the ENSO events in the tropical Pacific, the El Niño/La Niña events, since 1992. The second ocean indicator tracks the contracted or extended state of the Kuroshio Extension. The last ocean indicator is dedicated to the Ionian Basin in the Mediterranean Sea and permits separation of "zonal-cyclonic" state (19982005 and since 2011 up to now) from the "anticyclonic" state (1993-1996) usually discussed in the literature. In addition, it allows identifying a third state in which both the anticyclonic circulation around the northern part of the basin and the strong zonal Mid-Ionian Jet co-exist (2008-2010).
\end{abstract}

\section{Introduction}

The continuous monitoring of the ocean state, whose role in the earth's climate is central, has become essential both for scientific use and for informing intergovernmental bodies of the evolution of phenomena with a potentially high significant social impact. This can be efficiently done through the development of indicators that provide a synthetic overview of the state of the ocean climate and help to track trends over time and space. Several ocean state indicators already exist (see for example the climate indices published at the NOAA Earth System Research Laboratory website: http://www.esrl.noaa.gov/psd/data/climateindices/list/. Many of them are based on satellite sea surface temperature measurements like the Trans-Niño Index (TNI) and Niño 3.4 Index (Trenberth et al., 2001) in the Pacific Ocean, the Trop- ical Northern Atlantic (TNA) and Tropical Southern Atlantic (TSA) indices defined by Enfield et al. (1999) in the Atlantic Ocean, or the Western, Southeastern and Southwestern Tropical Indian Ocean (respectively the WTIO, SETIO and SWTIO) indices (Saji et al., 1999). Other observational sources may be used. For example, Curry and McCartney (2001) defined the Bermuda-Labrador Basin Transport Index, based on subsurface temperature and salinity data measured by ARGO floats, to monitor the strength of the transport in the subpolar and subtropical gyres in the North Atlantic, a key component of the ocean conveyor belt that affects worldwide climate and the ocean's inhabitants.

By providing sea surface height measurements globally and continuously, satellite altimetry is a key component of the global ocean observing system, perfectly suited for a global, continuous monitoring of the ocean variability. For several years, altimeter data have been used by different groups to generate global mean sea level trend indicators (for a recent review, see Meyssignac et al., 2012) that are regularly provided to intergovernmental bodies. A specific work has also been performed for the European Environment Agency (EEA) in order to provide European seas regional mean sea level trends for the EEA state of environment report (EEA, SOER 2010). The objective of this paper is to highlight the great potential of the altimeter observational system to monitor the ocean state through the generation of indicators. First, we show that altimeter data are as relevant as sea surface temperature data for monitoring the El Niño-Southern Oscillation (ENSO) events by generating an altimeter-based El Niño indicator. Then, we build two additional ocean indicators of well-known oceanic phenomena, i.e., the contracted/extended state of the Kuroshio Extension and the reversal of the surface circulation in the central part of the Mediterranean Sea (Ionian Basin). In both 
areas, biological and biogeochemical activities are quite sensitive to the underlying ocean dynamics, which makes the development of such ocean state indicators quite relevant. For example, the position of the Kuroshio strongly determines the regions where phytoplankton and hence fish are located. Consequently, the prediction and monitoring of the path of the Kuroshio is of huge importance for local fisheries and hence local economies (Kagimoto et al.,2008).

In the Mediterranean Sea, the reversal of the circulation in the central Ionian Basin has been shown to have a strong impact on nutrient distribution and availability as well as on plankton abundance and biodiversity pattern variability (Civitarese, 2010). Monitoring such changes is essential since the variation in biodiversity can have profound consequences on the functioning of local ecosystems.

In both areas, the changes in the current state show a clear signature in the eddy kinetic energy patterns, making the use of altimeter data perfectly suited to monitor the changes in these two regions.

Section 2 details the data and methods used to define the three indicators mentioned above. Sections 3, 4 and 5 describe respectively the El Niño indicator, the Kuroshio Extension indicator and the Ionian surface circulation indicator. The conclusion and perspectives are finally given in Sect. 6 .

\section{Data}

The altimeter data used in this study are provided by the DUACS system (Dibarboure et al., 2011) and operated by the Sea Level Thematic Assembly Center (SLTAC) of the MyOcean project (http://www.myocean.eu.org/). These products are obtained from the Level 2 altimeter data (i.e., Geophysical Data Record, GDR), available under three forms: Fast Delivery product and Intermediate product, both used in operational processing, and Delayed Time product, which is a reprocessed product. Although each altimeter mission is processed separately, consistency between the different missions is ensured by a homogenization process that consists of applying the most recent corrections, models and references recommended by agencies or expert groups. The up-to-date list of corrections and standards are given in the SSALTO/DUACS user handbook (2011). In addition, a multi-mission cross-calibration processing is applied to ensure consistency and accuracy of all the data flows from all satellites. Empirical processes are used to minimize longwave geographically correlated errors. First, a two-step orbit error reduction is applied using crossover minimization with a reference mission. Then, a second cross-calibration process is applied to reduce the residual long-wavelength error signal. Once altimeter data have been validated and intercalibrated, different sea level anomaly (SLA) products are generated using a reference sea surface corresponding to the 1993-1999 period. Data are first projected onto theoretical co-located track positions, using precise cross-track projec- tion and interpolation schemes. A final quality control processing is applied on these data to edit possible isolated and slightly erroneous measurements. Finally, information from the different altimeters is merged through an optimal interpolation to produce gridded SLA fields (Ducet et al., 2000).

The ocean variability can be studied directly from these maps of SLA (MSLA) or by differentiating them into eddy kinetic energy (EKE) through the geostrophic approximation formulae (Eq. 1).

$$
\begin{aligned}
& \mathrm{EKE}=\frac{1}{2}\left(u_{g}^{\prime 2}+v_{g}^{\prime 2}\right) \\
& \text { with } u_{g}^{\prime}=-\frac{g}{f} \frac{\partial \mathrm{SLA}}{\partial y} \text { and } v_{g}^{\prime}=+\frac{g}{f} \frac{\partial \mathrm{SLA}}{\partial x},
\end{aligned}
$$

where $g$ is the gravity and $f$ the Coriolis coefficient.

Maps of absolute dynamic topography (MADT) will also be used in the following to analyze surface circulation patterns. The MADT are obtained by adding the mean dynamic topography (MDT) to the MSLA (Eq. 2).

$$
\text { MADT }=\text { MSLA }+ \text { MDT }
$$

The MDT used in Sect. 3 is the CNES-CLS09 MDT (Rio et al., 2011), whereas the MDT used in Sect. 4 is a regional MDT (Rio et al., 2007) dedicated to the Mediterranean Sea. Both of them are computed using a combination of in situ data (surface drifting buoys, ARGO floats, CTD and XBT casts) and altimeter data.

SLTAC produces global $1 / 4^{\circ}$ gridded maps of the global ocean as well as $1 / 8^{\circ}$ gridded maps for regional seas as the Mediterranean Sea, the Black Sea and the Arctic Sea. Both Near Real Time (NRT) and Delayed Time (DT) maps are available (http://www.myocean.eu/web/ 24-catalogue.php). The ocean indicators described in this paper were developed using both DT and NRT products when available.

\section{Monitoring the El Niño-Southern Oscillation}

\subsection{Description of EI Niño-Southern Oscillation events}

The El Niño events in the equatorial Pacific belong to a broad disruption of normal weather patterns which cause drought, flooding and hurricanes around the world (Rasmusson and Wallace, 1983).

In normal conditions, easterly trade winds push surface Pacific waters towards Australia and the Philippines, creating a warm pool at the western end of the basin with higher temperatures and sea level (Philander, 1990). Over the ocean, these winds load up with moisture and release it as heavy rains over the warm pool. Meanwhile, at the eastern end of the basin, nutrient-rich cold waters upwell to the surface, favorable for fisheries (Barber and Chavez, 1983).

During an "El Niño" situation (McPhadden, 1999, 2004), westerly wind bursts at the western end of the basin and 
the warm pool drifts eastward into the central Pacific. The trade winds weaken and the storm zone moves eastward with the warm pool. Heavy rainfall floods coastal areas of western South America. The thermocline deepens and there is no longer upwelling of cold and nutrient-rich water off the coasts of Chile and Peru. The surface waters are warmer and fish stocks dwindle.

During "La Niña", which is somewhat the opposite of "El Niño", the trade winds strengthen, shrinking the warm pool and cooling the tropical Pacific. The climate becomes drier and colder off the coast of America. Rain is abundant over Indonesia and upwelling of cold water is more intense along the west coast of South America, leading to an abundance of anchovy (McPhadden, 2004).

\subsection{ENSO analysis with sea surface temperature}

As the ocean state linked to ENSO causes strong social and economical damages, several monitorings of the tropical Pacific have been already established (e.g., the TOGA/TRITON moored buoy array). UNESCO/IOC calculates weekly the Oceanic Niño Index (ONI) with the Reynolds OIv2 (Reynolds et al., 2002) sea surface temperature (SST) analysis, made available through the International Research Institute Data Library (http://iridl.ldeo. columbia.edu/index.html). The anomaly is calculated relative to a climatological seasonal cycle based on the years 1982-2005. For the same purpose, the National Oceanic and Atmospheric Administration (NOAA) analyses three-month running means of Extended Reconstructed SST (ERSST.v2) anomalies (Smith et al., 2004) in the Niño 3.4 region $\left(5^{\circ} \mathrm{N}-\right.$ $\left.5^{\circ} \mathrm{S}, 120-170^{\circ} \mathrm{W}\right)$. Episodes are identified using an ONI threshold of $\pm 0.5^{\circ} \mathrm{C}$, based on the $1971-2000$ period. For historical purposes, cold and warm episodes are defined when the threshold is met for a minimum of 5 consecutive overlapping seasons. Thus far, the sea surface temperature is the main variable used to monitor El Niño, in particular in the Niño 3.4 area.

\subsection{The altimetry-based EI Niño ocean indicator}

Altimetric sea level anomalies are a good candidate for providing information on El Niño. Since this area is already well studied, we first focus on the feasibility of using altimetry to build an El Niño ocean indicator before checking the relevancy of altimeter-based indicators for other areas. In order to compute an altimeter indicator for the El Niño/La Niña events, we first extracted the Niño 3.4 area from the $1 / 3^{\circ}$ global altimeter maps. The Delayed Time (DT) product is used when available since it is a consistent database using state-of-the-art recommendations from the altimetry community. However, there might be a lag of 6 months to a year between the availability of this dataset and present. The difference between the indices calculated from the two datasets is primarily a negative bias of the NRT compared to DT of the order of $1 \mathrm{~cm}$ or 0.1 in index value, when the same reference is used (i.e., MSLA from DT-UPD from 1993-2010, since a consistent NRT dataset over a long period is not available due to continuous upgrade of the NRT system without reanalysis). Near Real Time (NRT) products are thus used to complete the time series. In order to focus on the interannual signal, the biannual and annual cycles are removed from the data. Furthermore, a 60-day non-geophysical period is also removed in the altimeter products due to aliasing of tides, orbit and radiometer at the nearly 10-day repeat cycle from TOPEX and JASON. As mentioned earlier, the SLA delivered by the SLTAC are referenced to a $7 \mathrm{yr}$ time period (1993-1999). This is short compared to the SST availability period. We tested the impact of the reference period length on the results by using either a 7 or $14 \mathrm{yr}$ reference period. Similar indexes were obtained in both cases (not shown here). For better statistical representation, we set the reference period to the longest period currently available, i.e., 1993-2010. The SLA are thus calculated with respect to this mean. The index is built by dividing the SLA by the standard deviation (computed over the same reference period) and then averaging the values in the Niño 3.4 area. The output time series is also smoothed over 3 months to filter out high variability. The resulting time series is shown Fig. 1. An analysis is performed every week and published on the AVISO website.

We validate the obtained Niño index by applying the same process to Reynolds SSTs. The three indices NOAA ONI (1971-2000 based period), SST (1993-2006 based period) and SLA (1993-2006 based period) are very close to each other (Fig. 2). The comparison between the NOAA ONI and the SST mainly shows the impact of the reference period on the index, and the two collocated time series show a good 0.99 correlation. The SLA index compares well with the NOAA ONI (correlation of 0.88 ) and the SST index (correlation of 0.89 ). We conclude that the SLA index is an indicator of the ENSO as precise as the SST-based indicator (Fig. 1). Moreover, as SLA data reveal both steric effects in the whole water column and changes in the eustatic component of the sea level, the SLA-based index can therefore identify changes better than the SST-based index in areas where the subsurface steric effects or the eustatic component are assumed to dominate the variability.

\section{Monitoring the Kuroshio Extension}

\subsection{The Kuroshio Extension}

The Kuroshio Extension (KE) is an eastward-flowing inertial jet in the subtropical western North Pacific after the Kuroshio separates from the coast of Japan at $35^{\circ} \mathrm{N}, 140^{\circ} \mathrm{E}$. Being the extension of a wind-driven western boundary current, the KE has long been recognized as a current system rich in large-amplitude meanders and energetic pinched-off eddies (Qiu, 2003). The KE region has the largest sea-surface 

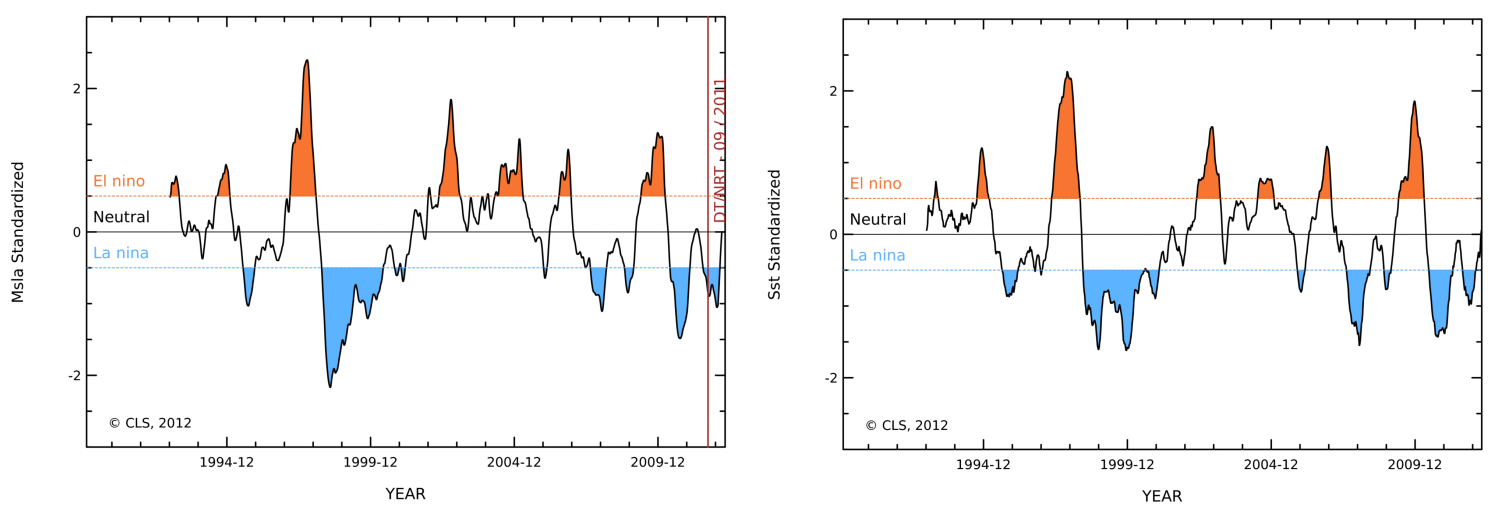

Fig. 1. Time series of SLA (left) and SST (right) divided by the respective standard deviation over the area and referenced to the 1993-2006 base period. In blue are La Niña events, in red El Niño.

NINO $3.4\left(170^{\circ} \mathrm{W}-120^{\circ} \mathrm{W}\right.$ and $\left.5^{\circ} \mathrm{S}-5^{\circ} \mathrm{N}\right)$

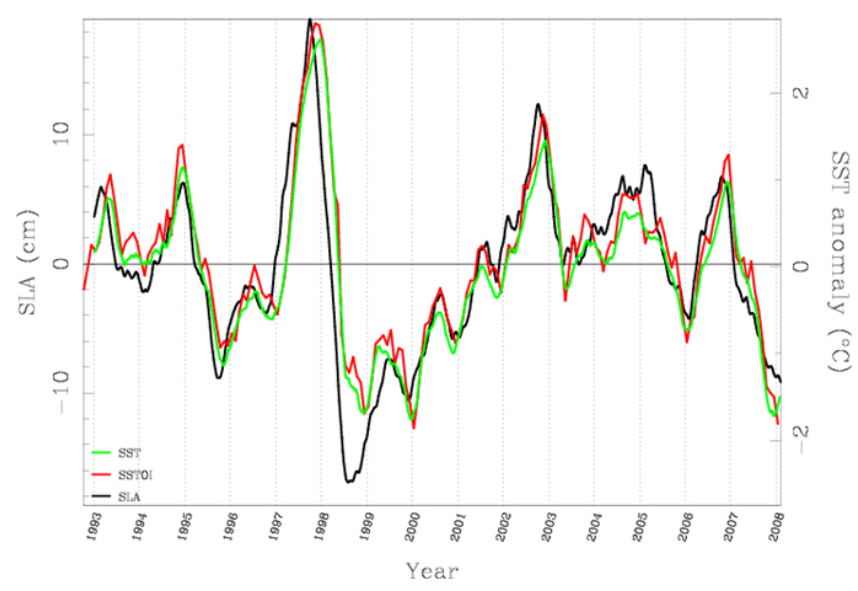

Fig. 2. Time evolution of SLA in black referenced to the 1993-2006 base period. In green the SST anomaly from Reynolds fields also referenced to the 1993-2006 base period, and in red the SST anomaly from NOAA ERSST.v2 fields referenced to the 1971-2000 base period. The latter is plotted from the ascii file obtained at ftp://ftp.cpc.ncep.noaa.gov/wd52dg/data/indices.

height variability on subannual and decadal timescales in the extratropical North Pacific Ocean (Qiu, 2002). The decadal variability is related to transitions of the KE from a highly energetic elongated path to a weaker contracted and more convoluted path (Qiu and Chen, 2005). The KE variability has been studied by numerous experimental studies, like WEST$\mathrm{PAC}$ at $152^{\circ} \mathrm{E}$, the Kuroshio Extension Region Experiment (KERE) at $143^{\circ} \mathrm{E}$ and the Kuroshio Extension System Study (KESS) at $146^{\circ} \mathrm{E}$, as well as by numerical studies (Kramer et al., 2011). Here, the long time series of Delayed Time SLTAC products are used to investigate the low-frequency changes of the Kuroshio Extension (KE) jet.

\subsection{Kuroshio Extension analysis with sea level}

The dominant low-frequency signal of the KE over the last seventeen years is characterized by a modulation of its zonal mean flow intensity (Qiu, 2003). This modulation results in two rather different states of the KE: an "elongated state" (also called "strong state") corresponding to a narrow strong steady jet (top right panel of Fig. 3), and a "contracted state" (also called "weak state") in which the jet is weaker and more unsteady, spreading on a wider latitudinal band (top left panel of Fig. 3). During the elongated time period, two quasistationary meanders are well developed with their ridges located at $144^{\circ}$ and $150^{\circ} \mathrm{E}$ (top and bottom right panel of Fig. 3, respectively), while they are barely discernible during contracted phases (top and bottom left panel of Fig. 3) (Qiu and Chen, 2005). South of the quasi-stationary meanders, the $\mathrm{KE}$ jet is flanked by a tight recirculation gyre whose circulation increases the eastward transport of the KE from the local Sverdrup transport (bottom right panel of Fig. 3). Between these two main states the KE jet has many intermediate states of transition and presents either progressively decreasing or strengthening trends. The decreasing (strengthening) of the zonal mean flow intensity can be connected with westward expansions of wind-induced sea level anomalies propagating by baroclinic Rossby waves (Qiu and Chen, 2005). These sea level anomalies are generated at midlatitudes in the eastern North Pacific by wind stress curl anomalies during the different phases of the Pacific Decadal Oscillation (PDO) (Qiu, 2003). Yet, El Niño-Southern Oscillation (ENSO) also generates low-latitude SSH (Sea Surface Height) anomalies that can be propagated northward at midlatitudes via western boundary currents and hence have a significant impact on the resulting SSH level of the KE region (Qiu and Lukas, 1996). The dominant interannual to decadal variability of the $\mathrm{KE}$ region is therefore connected with the two main largescale circulation oscillations of the Pacific: the PDO and the ENSO, with possible complex coupled interactions. 

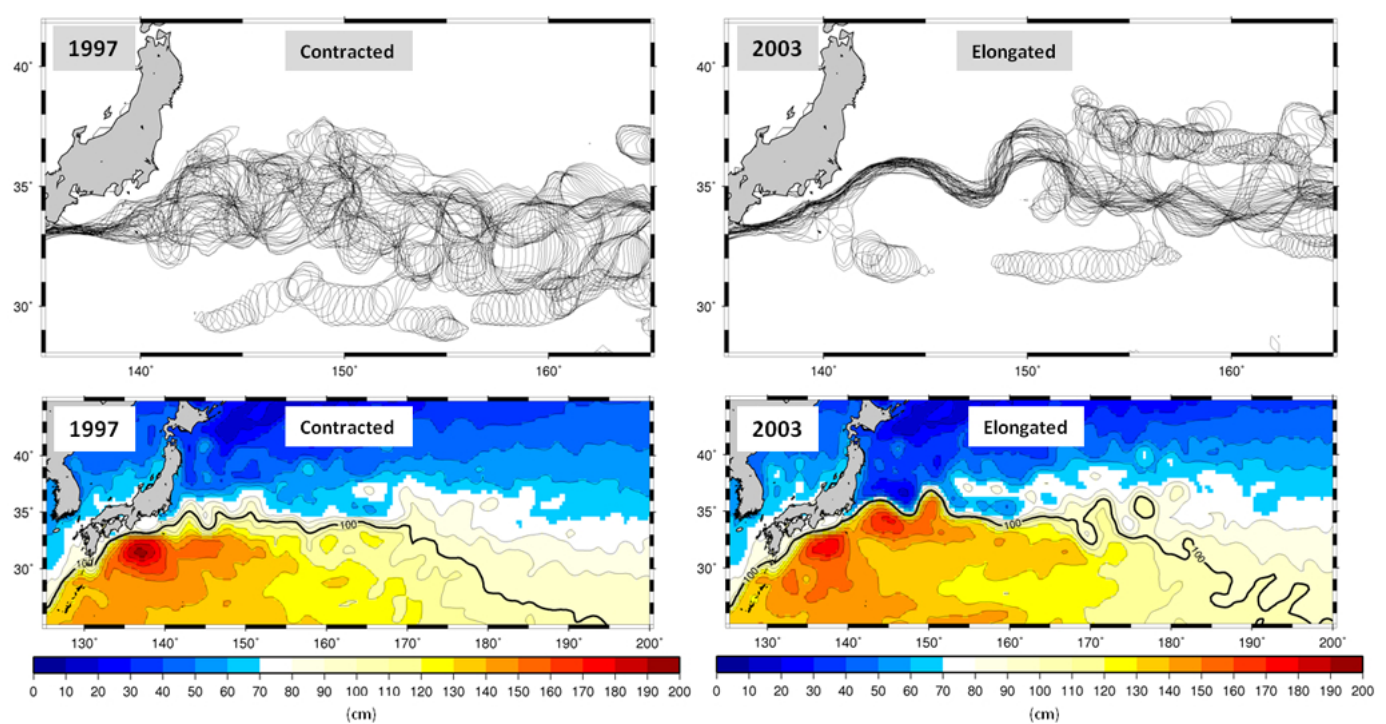

Fig. 3. Upper panels: yearly paths defined by the $100 \mathrm{~cm}$ contours in the weekly ADT (Absolute Dynamic Topography) fields for the 1997 contracted state (left) and the 2003 elongated state (right). Lower panels: yearly averaged ADT with a $10 \mathrm{~cm}$ contour interval and a thick line denoting $100 \mathrm{~cm}$ in the KE region during year 1997 (left) and year 2003 (right).
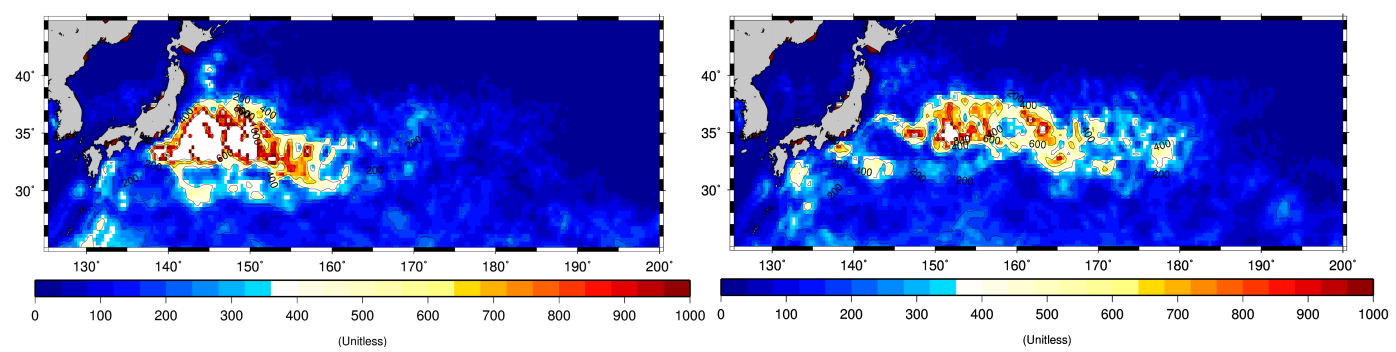

Fig. 4. Yearly averaged high-frequency EKE in the KE region during the 1997 contracted state (left panel) and the 2003 elongated state (right panel).

\subsection{The Kuroshio Extension altimetry-based indicator}

When the KE jet is in a weaker (stronger) state, the upstream KE path tends to become more (less) variable and regional eddy kinetic energy level tends to be higher (lower) (Fig. 4). Yet, this former relationship is rather counterintuitive since jet stability analysis usually suggests that stronger mean flows favor instabilities and lead to more mesoscale activities. This negative relationship between the strength of the KE jet and the EKE level is likely due to the interaction of the inflow KE jet with the Izu-Ogasawara shallow ridge south of Japan (Qiu and Chen, 2005). This plurality and variability of EKE sources suggest that the definition of an oceanic indicator of the Kuroshio jet state is not trivial. A way of characterizing the dynamics of the region and its variability is to decompose the high-frequency EKE (HF-EKE) into empirical orthogonal functions (Fig. 5). Following Brachet (2005), the HF-EKE is derived from the 200-day high pass filtered SLA in order to extract the mesoscale from the lowerfrequency signals. The HF-EKE is then centered and filtered with a 13-month moving average so as to remove the seasonal signal. The remaining variability modes are interannual to interdecadal modes. During the period 1993-2011, the first mode of the HF-EKE EOF (Empirical Orthogonal Function) decomposition accounts for $30 \%$ of the total variance. It exhibits a longitudinal spatial distribution of the signal both upstream $\left(141-153^{\circ} \mathrm{E}\right)$ and downstream $\left(153-165^{\circ} \mathrm{E}\right)$ of the $\mathrm{KE}$ jet, with a strong zonal gradient leading to a sign reversal about $150-155^{\circ} \mathrm{E}$ (top panel of Fig. 5). Combined with sign reversals of its temporal component (bottom panel of Fig. 5), this zonal out of phase in the spatial distribution of the variance generates a longitudinal bipolarity associated with the two opposite states of the KE jet (elongated vs. contracted). The maximum intensities are located upstream in the western part of the KE in the center of the positive cell.

To stick to the El Niño indicator definition strategy, we have tried to define an oceanic indicator based on a simple mean boxed EKE, so that this can be easily reproduced. The square box $\mathrm{B} 1=\left(142-149^{\circ} \mathrm{E}, 32-37^{\circ} \mathrm{N}\right)$ was 

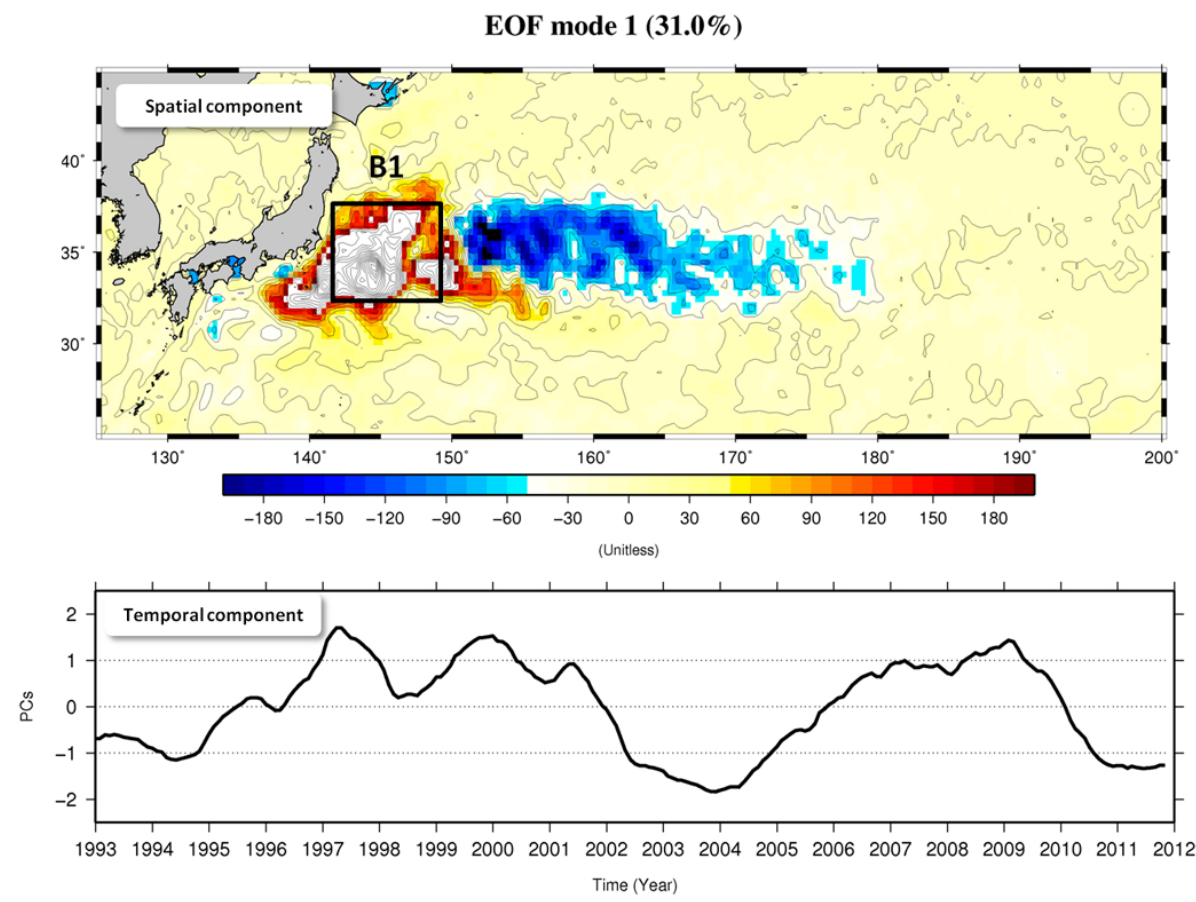

Fig. 5. Mode 1 spatial distribution of the 1993-2011 mean high-frequency EKE EOF decomposition in the KE region (upper panel) and its associated temporal component (lower panel). The box B1 is localized between $142-149^{\circ} \mathrm{E}$ and $32-37^{\circ} \mathrm{N}$ in the top panel.

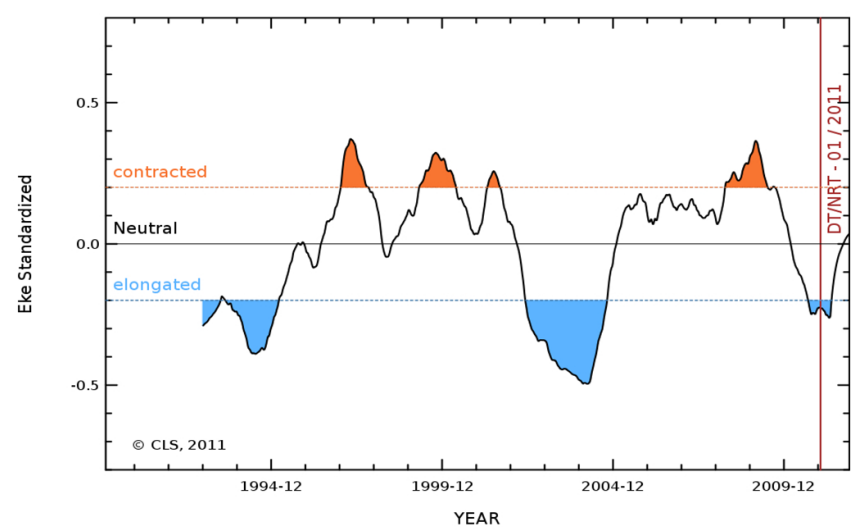

Fig. 6. Mean standardized HF-EKE defined in box B1 in the KE region during the period 1993-30 November 2011 (see Fig. 5 for B1 spatial location). Blue shaded areas correspond to elongated state periods, while orange shaded areas fit contracted state periods. The vertical red line indicates the transition between the Delayed Time (DT) and the Near Real Time (NRT) production modes of the SLA used for the HF-EKE calculation.

found to catch most of the positive pattern when averaging the HF-EKE (Fig 5). The temporal evolution of the mean standardized HF-EKE defined in box B1 during the period 1 January 1993-30 November 2011 (Fig. 6) shows similar variations to those obtained for temporal component of the first mode in the HF-EKE EOF decomposition method (bottom panel of Fig. 5). Blue shaded areas correspond to elongated states periods (1993-1994, 2002-2004 and 2010-2011), while orange shaded areas fit contracted states periods (1997-2001 and 2009). For each year of the orange and blue shaded periods, the yearly path (as defined in Fig. 6, two top panels) always matches one of the two patterns of Fig. 5. Between these two opposite phases the KE jet has many intermediate states of transition and presents either progressively decreasing (1994-1997 and 2004-2009) or strengthening (2001-2002 and 2009-2010) trends.

\section{Monitoring the surface circulation in the Ionian Basin, Mediterranean Sea}

\subsection{Decadal oscillations of the Ionian surface circulation}

The dominant low-frequency dynamic of the Ionian Sea over the last twenty years is characterized by a decadal oscillation of its upper layer basin-wide circulation. This modulation results in two rather different states of the Ionian surface circulation (IoSC) associated with a reversing of the circulation 1 in the northern part of the Ionian Sea from a cyclonic mode (also called zonal mode) to an anticyclonic mode and vice versa (e.g., Pinardi et al., 1997; Pujol and Larnicol, 2005; Hamad et al., 2005; Gačić et al., 2011). The "anticyclonic state" corresponds to the presence of an anticyclonic gyre in the northern part of the Ionian Basin (namely 



$\begin{array}{lllllllllllllllllllll}0 & 10 & 20 & 30 & 40 & 50 & 60 & 70 & 80 & 90 & 100 & 110 & 120 & 130 & 140 & 150 & 160 & 170 & 180 & 190 & 200\end{array}$

(Unit: $\mathrm{cm}$ )

Fig. 7. Yearly averaged ADT with a $10 \mathrm{~cm}$ contour interval and a thick line denoting $100 \mathrm{~cm}$ in the KE region from year 1993 (upper left panel) to year 2011 (lower right panel). Data of the Near Real Time (NRT) production mode are used during year 2011, from 26 January to 30 November. Unit in $\mathrm{cm}$.

the anticyclonic North Ionian Gyre (NIG)) and is associated with a weak quasi-zonal jet crossing the Ionian Sea from the west to the east, namely the Mid-Ionian Jet (MIJ), top right panel of Fig. 9. Conversely, the "cyclonic state" is related to a reversal of the NIG (cyclonic NIG) and is associated with an intense MIJ (bottom right panel of Fig. 9). Between these two main states, the IoSC has many intermediate states of transition and presents either progressively decreasing or strengthening trends.

During the 1990s, a transition of deep water formation areas occurred from the Southern Adriatic Sea to the Cretan Sea. This transition is called the Eastern Mediterranean Transient (EMT) and was followed by a massive dense-water out- put of Cretan Sea Outflow Water (CSOW) from the Aegean Sea (Roether et al., 2007). Before 1997, the CSOW set up a bottom pressure gradient directed towards the center of the basin and capable of sustaining a stationary cyclonic shear in the bottom layer. The resulting raising of isopycnes subsequently generates an anticyclonic shear in the upper layer (Borzelli et al., 2009). Conversely, after 1997 the outflowing Adriatic dense water set up a bottom pressure gradient able to sustain a stationary anticyclonic shear in the bottom layer and a cyclonic one in the upper layer.

In the following sections, nineteen years of SLTAC/DUACS altimeter data have been used to investigate the low-frequency changes in the Ionian general 


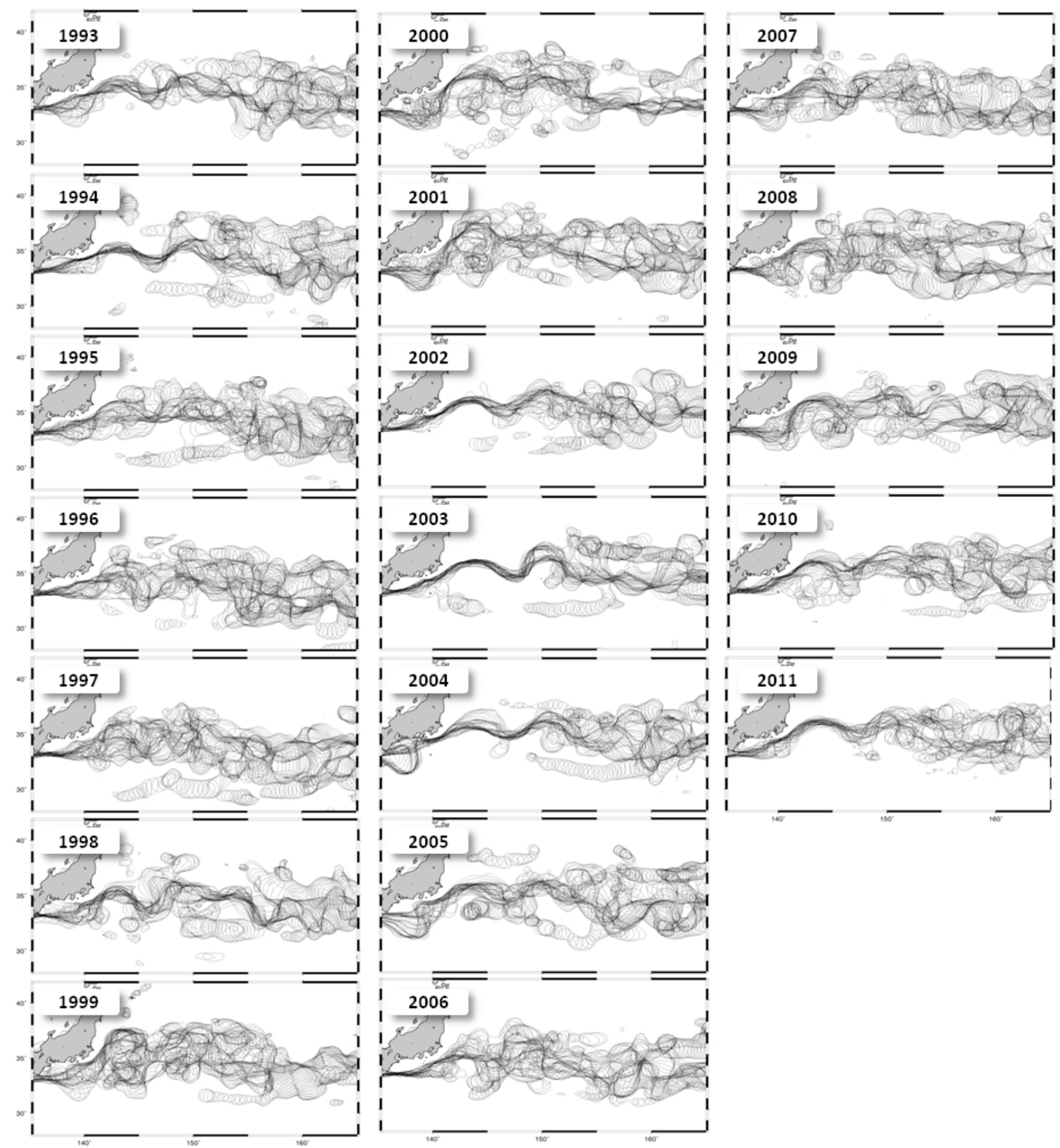

Fig. 8. Yearly path defined by the $100 \mathrm{~cm}$ contours in the weekly ADT fields in the KE region from year 1993 (upper left panel) to year 2011 (lower right panel). Data of the Near Real Time (NRT) production mode are used during year 2011, from 26 January to 30 November.

surface circulation, in order to define an efficient oceanic indicator of the different IoSC phases.

\subsection{Ionian surface circulation analysis with sea level}

The setting up of an oceanic indicator of the alternate IoSC phases - a question that has not been addressed yet in the literature - is confronted with the same difficulties as the 


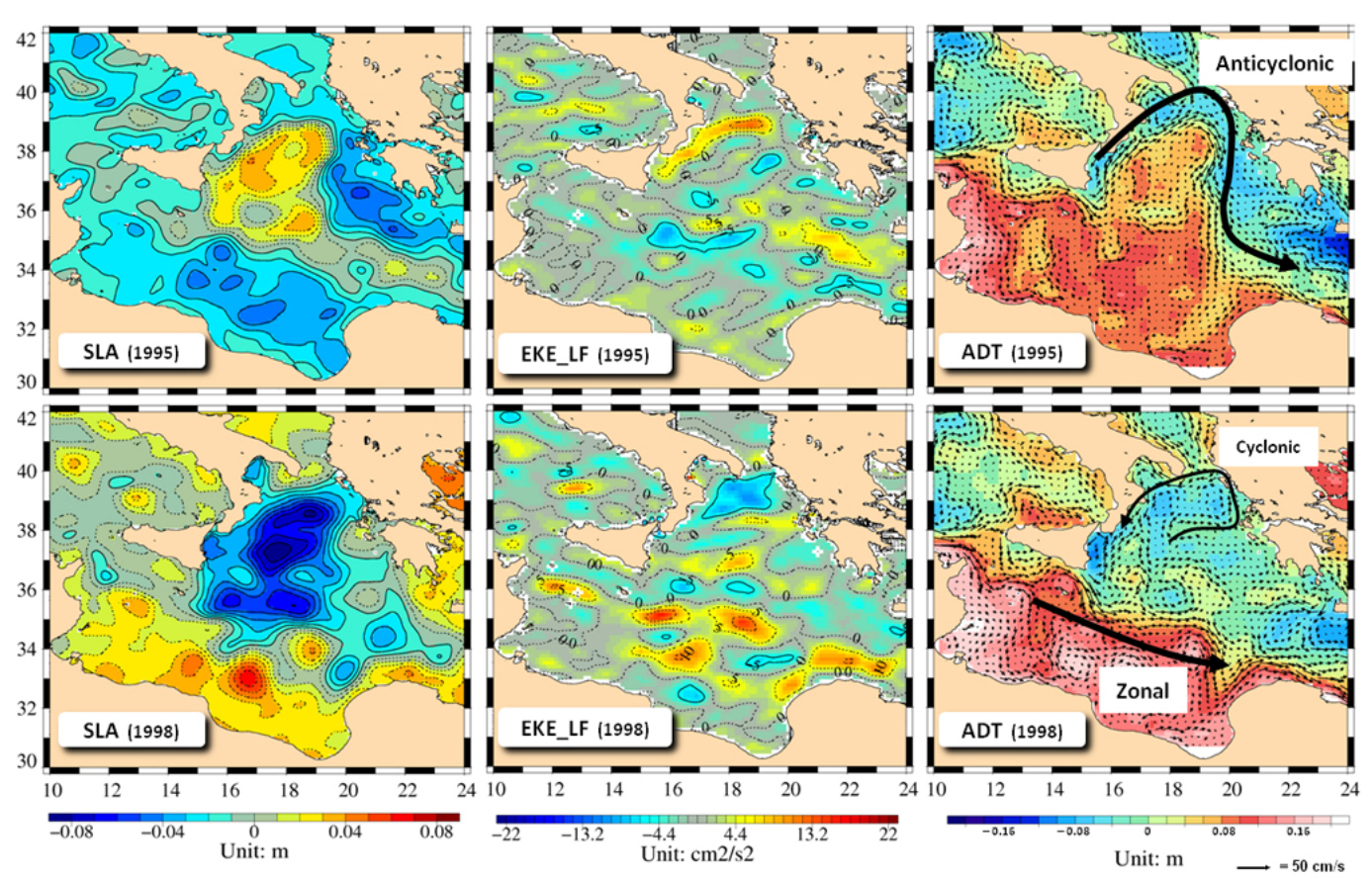

Fig. 9. Yearly averaged SLA, centered low-frequency EKE (LF-EKE) and ADT with overlaid total velocity field (left, middle and right panels, respectively) in the Ionian region during year 1995 (top panels) and year 1998 (bottom panels). Units respectively in $\mathrm{m}, \mathrm{cm}^{2} \mathrm{~s}^{-2}$ and $\mathrm{m}$. Vector field scale: $50 \mathrm{~cm} \mathrm{~s}^{-1}$.

comprehension of the general circulation in the basin, i.e., the plurality of the mechanisms brought into play and their possible interactions and feedback mechanisms on decadal timescales. Its determination is also made delicate since different types of circulations occur in opposite parts of the basin: quasi-zonal jet circulation in the central and southern parts of the basin versus cyclonic-anticyclonic gyre circulations in the northern part. As for the determination of the oceanic indicator of the Kuroshio jet state, we applied an EOF decomposition analysis on the altimeter signal. Yet, as shown by a qualitative comparison between top-left and bottom-left panels of Fig. 9, the choice of the SLA as a tracer of the northern IoSC inversions seems to be a more appropriate choice than an EKE based tracer. Thereafter, the SLA has been filtered with a 13-month moving average in order to remove the seasonal signal so as to concentrate on interannual to interdecadal modes. During the period 1993-2011, the first mode of the SLA decomposition is responsible for $48 \%$ of the total variance, while mode 2 accounts for $14.0 \%$ of the total variance in the Mediterranean Sea (top panel of Fig. 10. The spatio-temporal characteristics of mode 1 are in agreement with trend characteristics found by CriadoAldeanueva et al. (2008) for the period 1992-2005 and by Vigo at al. (2011) for the period 1992-2008 (not shown). Therefore, the first mode is related to non-seasonal steric and mass-induced contribution, i.e., the non-seasonal component of the trend. The spatial structure of mode 2 is characterized by a high-amplitude circular pattern in the northwestern part of the Ionian (top panel in Fig. 10). The temporal variations of mode 2 amplitude reveal prevalently decadal variability (bottom panel in Fig. 10). The high-amplitude circular feature of mode 2 coincides with the cyclonic-anticyclonic NIG circulation pattern as evidenced from the yearly average ADT current fields (Fig. 16). Therefore, the inversions of the NIG are associated with sign reversals of the temporal component in mode 2. Figure 10 shows that the temporal locations of the NIG inversion is in good agreement with what is expected for the cyclonic-anticyclonic inversion at the end of year 2005, while the anticyclonic-cyclonic inversion of year 1997 occurs later in 1998. Moreover, unlike what can be observed in Fig. 10 for year 1994, the anticyclonic circulation pattern is missing in Fig. 10. A more precise view can be obtained using a square box $\mathrm{S} 1=\left(15-20^{\circ} \mathrm{E}, 35-40^{\circ} \mathrm{N}\right)$ (marked in Fig. 10), in order to catch most of the mode 2 northwestern circular pattern when averaging the SLA. The temporal evolution of the mean SLA defined in box S1 during the period 1993-2011 is shown in Fig. 11.

Its variations of the first order are similar to those obtained with the temporal component of the second EOF mode of SLA. Furthermore, the north-Ionian-focused box average method enables fitting the anticyclonic period of 1993-1996 and its inversion toward cyclonic period with what is observed on yearly average ADT fields (Fig. 12).

Concerning the cyclonic period of 1998-2005, note that in spite of similar amplitudes of mean boxed SLA in both phases of the NIG, maps of ADT with overlaid total velocity 

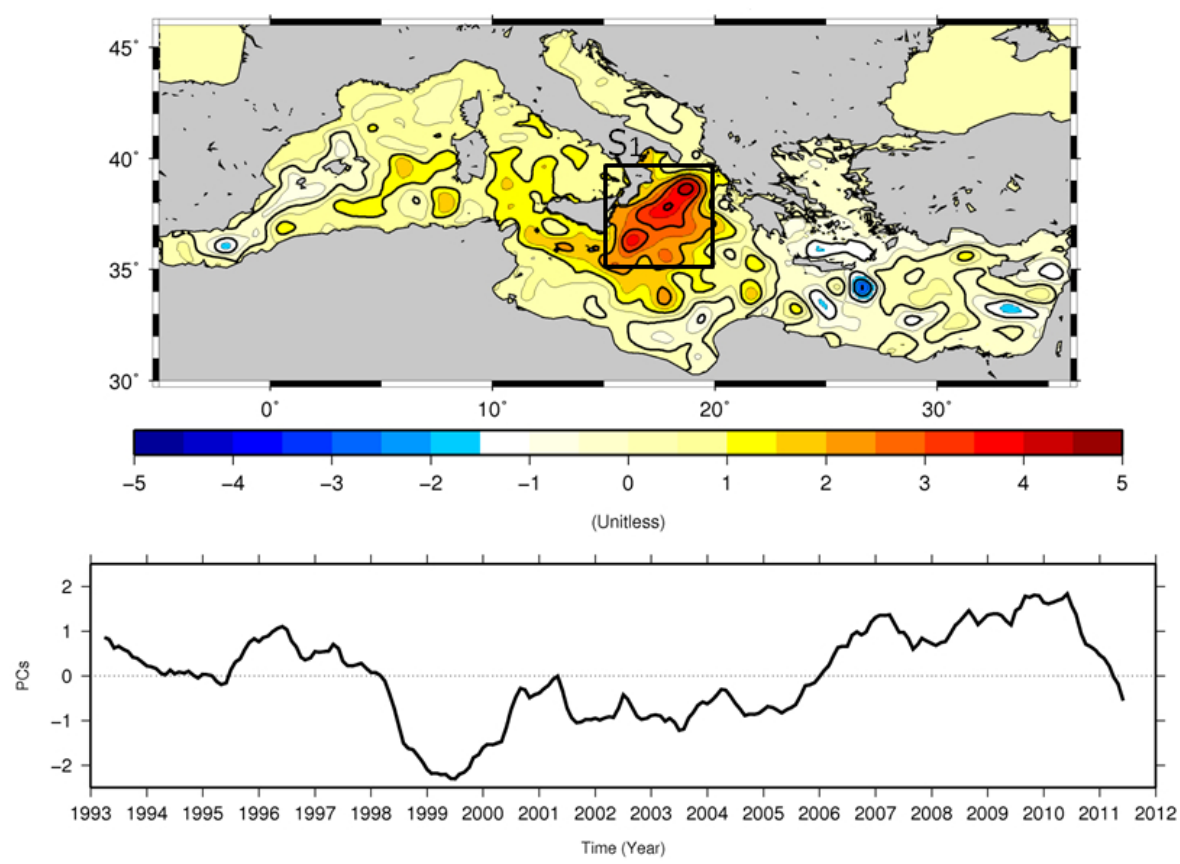

Fig. 10. Mode 2 spatial distribution of the 1993-2011 mean SLA EOF decomposition in the Mediterranean Sea (top panel) and its associated temporal component (bottom panel). This mode explains $14.0 \%$ of the total variance. The box S1 is localized between $15-20^{\circ} \mathrm{E}$ and $35-40^{\circ} \mathrm{N}$ in the top panel.

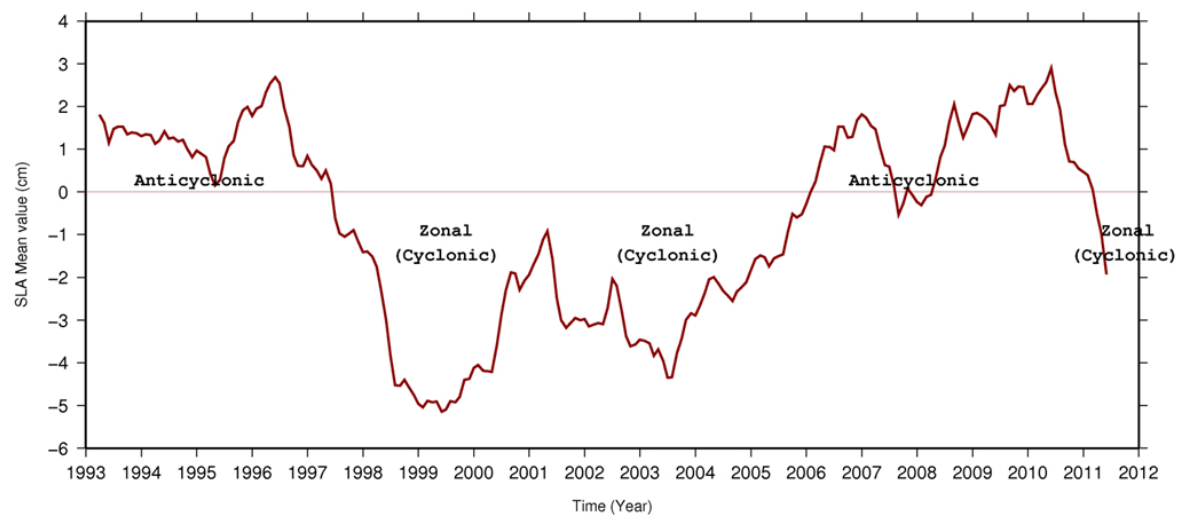

Fig. 11. Time series in the Ionian region during the period 1993-2011 of mean SLA in box S1 as defined in Figure 10 (top panel), units in $\mathrm{cm}$. The red level is shown in order to differentiate the NIG phases: the "anticyclonic" phases (above red level) and the "cyclonic" phases (under red level).

fields reveal an asymmetry in the velocity intensities according to the phase of the NIG. The mean total velocity modulus defined in box S1 during the period 19932011 reveals significantly higher intensities during anticyclonic NIG (about $5 \mathrm{~cm} \mathrm{~s}^{-1}$ ) than during cyclonic NIG (about $0.8 \mathrm{~cm} \mathrm{~s}^{-1}$ ). Thus, as confirmed by the yearly average ADT fields (Fig. 12) the surface signature of the cyclonic NIG may be almost unnoticeable during cyclonic period, which is problematic for an oceanic indicator based on surface remote sensing. Yet, as observed by Pujol and Larnicol (2005), the intensity of the MIJ increases during the cyclonic period after 1997. This predominance of the MIJ compared to the cyclonic NIG can be observed on the yearly average ADT fields during the period 1998-2005 (Fig. 12). It must be noticed that though possible, an overestimation of the MIJ in the MDT field remains weak since: (i) unlike near the coasts, data sampling make it possible to correctly detect the stream in the central part of the basin, (ii) altimeter errors in that part of the basin are weaker than close to the coasts, (iii) the spatial distribution of the low-frequency EKE (i.e., derived from the 100-day low-pass filtered SLA) in the yearly and monthly average fields (not shown) is consistent with the existence of 




$$
\begin{array}{lllllll}
-0.2 & -0.12 & -0.04 & 0.04 & 0.12 & 0.2 & \text { (Unit: } \mathbf{m})
\end{array}
$$

Fig. 12. Yearly averaged ADT with overlaid total velocity field in the Ionian region from year 1993 (upper left panel) to year 2011 (lower right panel). Units in $\mathrm{m}$, vector field scale: $50 \mathrm{~cm} \mathrm{~s}^{-1}$.

an intense MIJ, and (iv) using drifters Gerin et al. (2009) have shown that the main feature for the year 2005 is an eastward flow entering the Sicily Strait and crossing the Ionian in its central part. That is why in term of surface circulation, talking about "cyclonic-zonal" state instead of a fully "cyclonic" state seems to be justified.

Besides the two main patterns of circulation (fully anticyclonic and cyclonic-zonal), a mixed state is also possible in which the anticyclonic NIG coexists with the zonal MIJ as during year 2007 (right panel of Fig. 13). Contrary to year 1997 , this state is not a temporary transition since it has lasted
$4.5 \mathrm{yr}$ from the cyclonic-anticyclonic inversion of the end of year 2005 to the middle of year 2010.

As for the cyclonic year 1998 (bottom-middle panel of Fig. 9), the MIJ signature is noticeable in the spatial distribution of the 2007 yearly averaged low-frequency EKE (LF-EKE) (middle panel of Fig. 13). Yet, unlike for years 1995 and 1998, the spatial distribution of the 2007 yearly averaged SLA does not present a latitudinal bipolarity associated with the northern and the southern parts of the Ionian. Instead, the spatial distribution of the SLA for year 2007 is basically different since alternate mesoscale SLA structures fill the whole basin (left panel of Fig. 13). These 


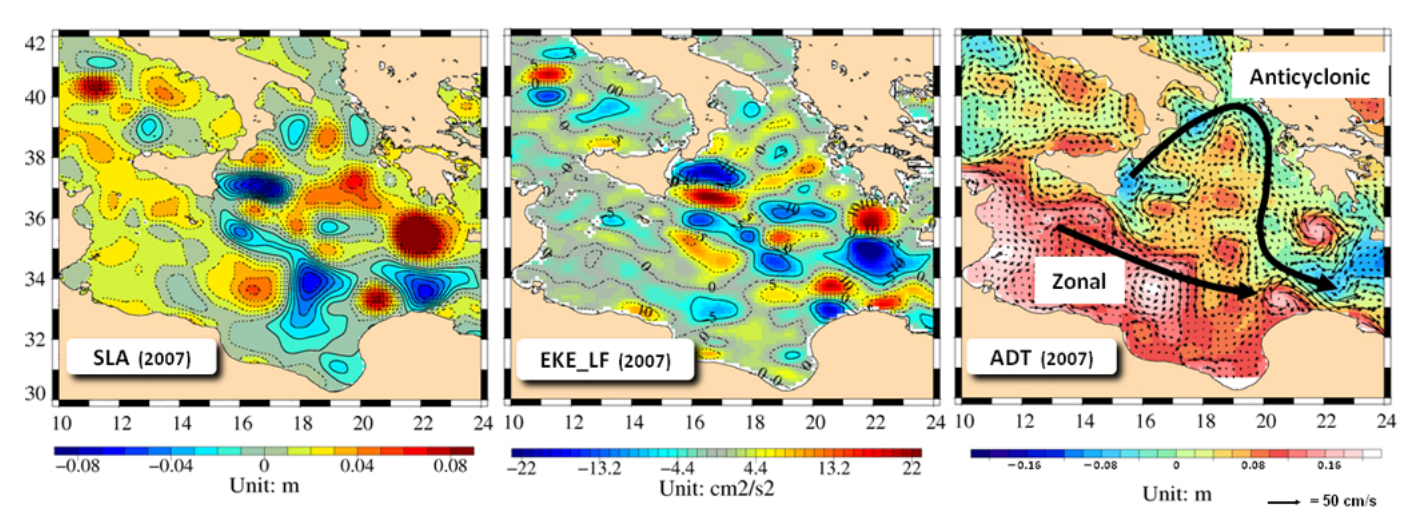

Fig. 13. Yearly averaged SLA, centered LF-EKE and ADT with overlaid total velocity field (left, middle and right panels, respectively) in the Ionian region during year 2007. Units respectively in $\mathrm{m}, \mathrm{cm}^{2} \mathrm{~s}^{-2}$ and $\mathrm{m}$. Vector field scale: $50 \mathrm{~cm} \mathrm{~s}^{-1}$.
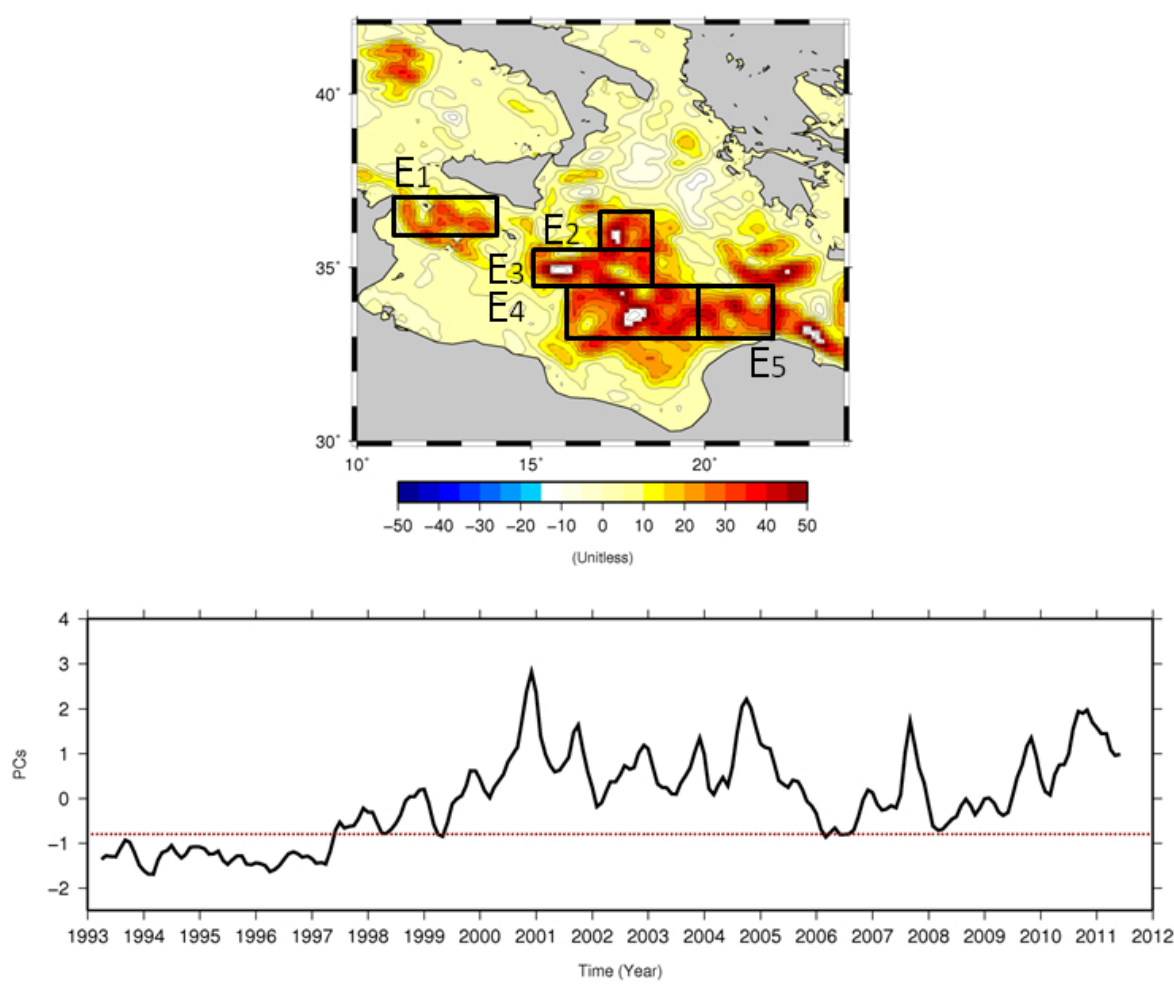

Fig. 14. Mode 1 spatial distribution of the 1993-2011 mean low-frequency EKE EOF decomposition in the Ionian region (top panel) and its associated temporal component (bottom panel). This mode explains $12.0 \%$ of the total variance. The level corresponding to -0.9 has been mentioned in order to differentiate phases of weak/strong LF-EKE intensities in relation with the absence/presence of the MIJ, respectively. Five boxes are localized on top panel: $\mathrm{E} 1=\left[11-14^{\circ} \mathrm{E}, 36-37^{\circ} \mathrm{N}\right], \mathrm{E} 2=\left[17-18.5^{\circ} \mathrm{E}, 35.5-36.5^{\circ} \mathrm{N}\right], \mathrm{E} 3=\left[15-18.5^{\circ} \mathrm{E}, 34.5-35.5^{\circ} \mathrm{N}\right]$, $\mathrm{E} 4=\left[16-19.5^{\circ} \mathrm{E}, 33-34.5^{\circ} \mathrm{N}\right]$ and $\mathrm{E} 5=\left[19.5-22^{\circ} \mathrm{E}, 33-34.5^{\circ} \mathrm{N}\right]$.

discrepancies (similarities) concerning the SLA (LF-EKE) can be generalized for all years over the period 2006-2010 when compared with all years of either the anticyclonic period of 1993-1996 or the ones of the cyclonic period 19982005 (not shown), which tends to prove that the circulation pattern observed during the period 2006-2010 is related to a third "anticyclonic-zonal" state of the IoSC. Therefore, an oceanic indicator that would be only based on mean boxed
SLA would not be able to discriminate fully "anticyclonic" state period (e.g., 1993-1996) from an "anticyclonic-zonal" state period (e.g., 2006-2010).

\subsection{Ionian surface circulation analysis with EKE}

The presence/absence of the MIJ distinguishes fully "anticyclonic" from "anticyclonic-zonal" state period (Fig. 12). The 


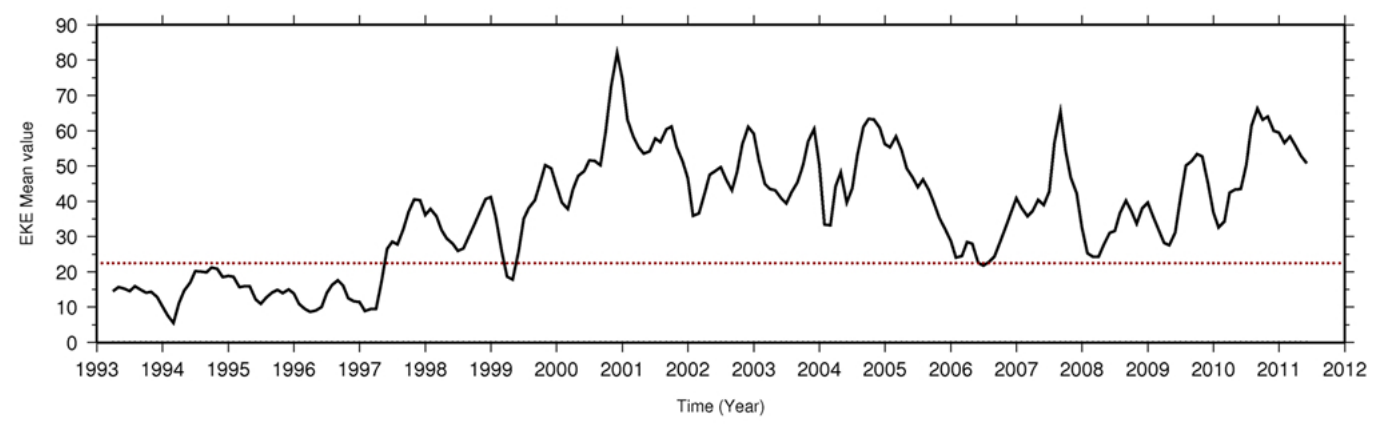

Fig. 15. Time series of mean LF-EKE in boxes E1 + E2 + E3 + E4 + E5 as defined in Fig. 14 during the period 1993-2011. Units in $\mathrm{cm}^{2} \mathrm{~s}^{-2}$.

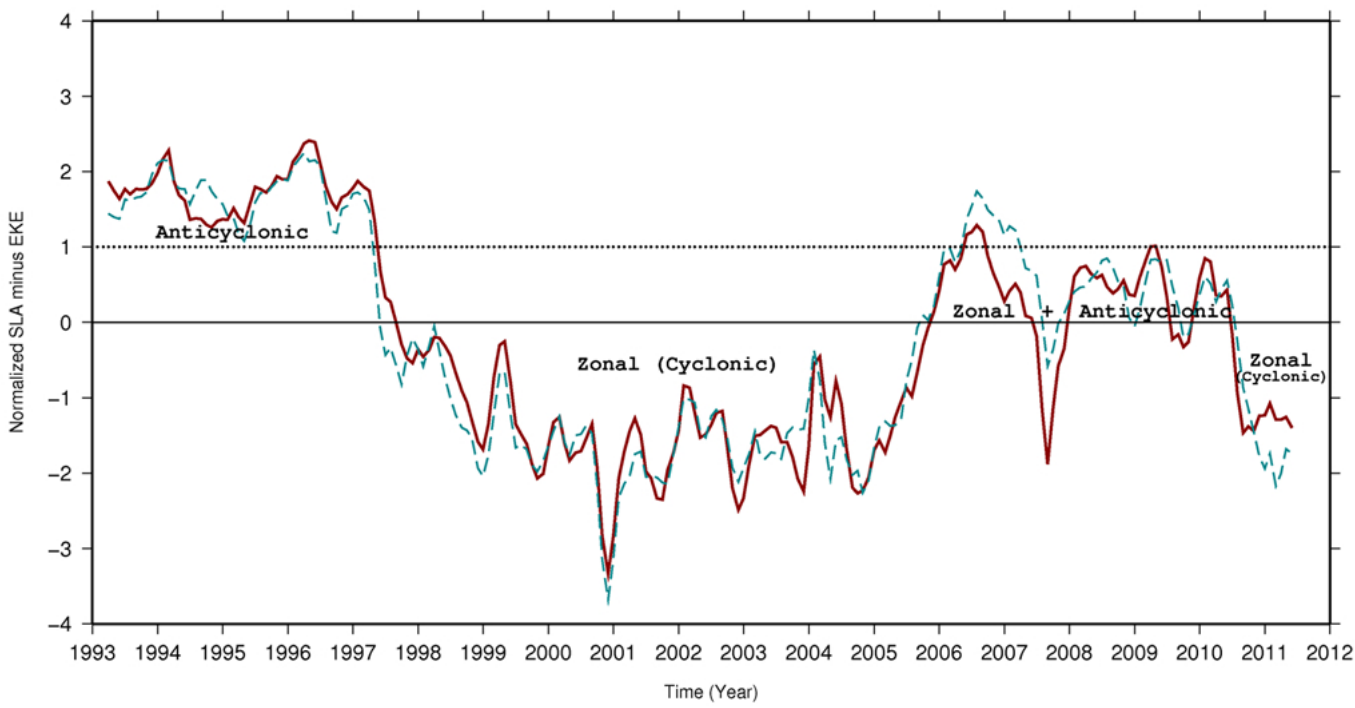

Fig. 16. Time series of mean standardized SLA minus mean standardized LF-EKE in previously defined respective boxes in the Ionian region during the period 1993-2011: average in boxes S1 and E1 + E2 + E3 + E4 + E5 (red line) and average in S1 and E2 + E3 + E4 (blue dashed line). Level 0 and level 1 have been mentioned in order to differentiate surface circulation phases.

SLA signature of the MIJ is weak (bottom left panel of Fig. 9 and top panel of Fig. 10); however, as jets are likely to generate intense SLA gradients, their surface signature should be seen in the EKE field. The total EKE decomposition in HF-EKE and LF-EKE has been deduced, respectively, from the low- and the high-frequency component of the SLA, both computed applying a Loess low-pass time filter to the SLA signal in order to extract a signal higher and lower than 100 days. As underlined by Pujol and Larnicol (2005), LF-EKE clearly evidences the variability of the intensity of the MIJ, while HF-EKE rather traduces the mesoscale activity linked to the MIJ. In the following, we thus focus on the LF-EKE component. Following Brachet (2005), the LF-EKE is then centered and filtered with a 13-month moving average so as to remove the seasonal signal. Therefore, remaining variability modes are interannual to interdecadal modes.

During the period 1993-2011, the mode 1 of the LF-EKE EOF decomposition accounts for about $12 \%$ of the total vari- ance in the Ionian Basin. Top panel of Fig. 14 shows a quasizonal spatial distribution of the signal crossing the central part of the Ionian from the Sicily Strait to the Cretan Passage and associated with the MIJ trajectory. The meridional spreading of the pattern (about $4^{\circ}$ of latitude at $17^{\circ} \mathrm{E}$ ) is related to the intense MIJ low-frequency dynamics and instabilities subsequently responsible for the intense mesoscale variability in that part of the basin (Hamad et al., 2005). Therefore, weak LF-EKE intensities correspond to the absence or to a weak activity of the MIJ, while strong LF-EKE intensities are the signature of a strong activity of the MIJ. The level corresponding to -0.9 has been indicated in Fig. 14 in order to link phases of weak/strong LF-EKE intensities with respect to the absence/presence of the MIJ, respectively (Fig. 12).

As for the mean boxed SLA, the possibility to obtain a more precise view has been tested by using square boxes for average. Numerous sensibility tests have been 
done concerning the box locations in order to catch the highest level of variability and to accentuate previous evidenced states of the IoSC. Location of retained boxes is mentioned on top panel of Fig. 14: $\mathrm{E} 1=\left[11-14^{\circ} \mathrm{E}\right.$, $\left.36-37^{\circ} \mathrm{N}\right], \quad \mathrm{E} 2=\left[17-18.5^{\circ} \mathrm{E}, \quad 35.5-36.5^{\circ} \mathrm{N}\right], \quad \mathrm{E} 3=[15-$ $\left.18.5^{\circ} \mathrm{E}, \quad 34.5-35.5^{\circ} \mathrm{N}\right], \quad \mathrm{E} 4=\left[16-19.5^{\circ} \mathrm{E}, \quad 33-34.5^{\circ} \mathrm{N}\right]$ and $\mathrm{E} 5=\left[19.5-22^{\circ} \mathrm{E}, 33-34.5^{\circ} \mathrm{N}\right]$. Following Gačić et al. (2011) and Robinson et al. (1991), the averaging area has not been extended towards high levels of variability south of the Peloponnesos coast in order to avoid the noise introduced by the Pelops Gyre. The temporal evolution of the mean LF-EKE defined in boxes E1 + E2 + E3 + E4 + E5 during the period 1993-2011 is shown in Fig. 15. Its variations are almost identical to those obtained with the temporal component of the LF-EKE EOF first mode. As in Fig. 14, a horizontal level $\left(22.5 \mathrm{~cm}^{2} \mathrm{~s}^{-2}\right)$ has been chosen that allows differentiation of phases of weak LF-EKE intensities (i.e., corresponding to the absence or to a weak activity of the MIJ) from phases of strong LF-EKE intensities (i.e., corresponding to a strong activity of the MIJ). The mean boxed LF-EKE of Fig. 15 confirms the absence or the weak activity of the MIJ during the fully "anticyclonic" period of 1993-1996, while it clearly shows an intense activity of the MIJ during both the "cyclonic-zonal" period of 1998-2005 and the "anticyclonic-zonal" period of 2006-2010.

Therefore, an oceanic indicator that would be only based on mean boxed LF-EKE would not be able to discriminate the "cyclonic-zonal" state period (e.g., 1998-2005) from the "anticyclonic-zonal" state period (e.g., 2006-2010).

\subsection{The IoSC altimetry-based indicator}

Thus, it is possible and necessary to combine the oceanic indicator based on mean boxed SLA with the one based on mean boxed LF-EKE in order to discriminate fully the "anticyclonic" state during which the MIJ is absent (period 1993-1996) from those in which the anticyclonic NIG is able to coexist with an intense zonal MIJ (period 2006-2010). The time series of the mean standardized SLA minus the mean standardized LF-EKE as previously defined in boxes $\mathrm{S} 1$ (Fig. 10) and E1 + E2 + E3 + E4 + E5 (Fig. 14) is shown during the period 1993-2011 (Fig. 16, red line).

Level 0 and level 1 have been mentioned in Fig. 16 in order to differentiate the 3 Ionian surface circulation phases: the "fully anticyclonic" phases (above level 1), the "zonal-cyclonic" phases (under level 0) during which the cyclonic surface circulation may disappear, and the mixed "anticyclonic-zonal" phases (between level 0 and level 1) in which the coexistence of the two former states is possible. Transition phases also appear between level 0 and level 1 , as during year 1997. Note that the downward peak occurring during year 2007 in Fig. 16 is partly due to a strong anomaly of LF-EKE as shown in Fig. 14. Yearly (Fig. 12) and monthly average ADT fields (not shown) indicate that these intense LF-EKE values are partly associated with stationary Libyan mesoscale eddies, also observed in Gerin et al. (2009). This downward peak may be weakened by choosing another set of boxes, i.e., $\mathrm{S} 1$ and $\mathrm{E} 2+\mathrm{E} 3+\mathrm{E} 4$, that is, in a region restricted to the highest variability areas and located closer to the central part of the Ionian Basin (blue line in Fig. 16). During the "anticyclonic" and "zonal-cyclonic" phases, the red and blue lines of Fig. 16 are very similar, which demonstrates the robustness of the indicator. The mixed "anticyclonic-zonal" phase of years 2006 and 2007 seems to be more sensitive to box location, which may be due to its more unsteady nature.

Finally, the oceanic indicator of Fig. 16 reveals that the well-discussed reversals of year 1997 and 2005 are followed by another transition from "anticyclonic-zonal" mode to "cyclonic-zonal" mode, which took place in the middle of the year 2010. This observation is strengthened by yearly (Fig. 12) and monthly average ADT fields (not shown). We conclude that the low-frequency changes in the IoSC do not correspond to strictly decadal oscillations.

\section{Conclusion and perspective}

In this paper, new ocean state indicators have been derived from the SLTAC/DUACS altimeter dataset. They enable monitoring three well-known phenomena, the ENSO events in the tropical Pacific, the Kuroshio Current Extension state in the northwestern Pacific and the Ionian surface circulation reversal in the Mediterranean Sea. These indicators were obtained by averaging into specific boxes the altimeter sea level anomaly or derived eddy kinetic energy information. Except for the ENSO indicator, for which the Niño 3.4 box is used (initially defined for computing SST-based indices), the relevant boxes have been defined in order to best reproduce the principal component time series of the EOF variability mode corresponding to the dynamical phenomena for monitoring. The indicator developed in the Kuroshio area clearly allows the elongated states periods (1993-94, 2002-2004 and 2010-2011) to be distinguished from the contracted states periods (1997-2001 and 2009). The indicator developed in the Mediterranean Sea permits separation of the "zonal-cyclonic" state (1998-2005 and since 2011 up to now) from the "anticyclonic" state (1993-1996) usually discussed in the literature when describing the general surface circulation pattern of the Ionian Sea. In addition, it allows identification of a third state in which both the anticyclonic circulation around the northern part of the basin and the strong zonal Mid-Ionian Jet co-exist (2006-2010).

These three indicators will now be updated at each Delayed Time reprocessing but also all along the Near Real Time production.

In the future, we want to compare the Kuroshio and the Ionian Sea ocean state indicators with other available independent data (e.g., SST and surface drifter data), as done for the Oceanic Niño Index. Furthermore, we plan to extend our work to other well-known climatic phenomena, like for 
instance the Western Tropical Indian Ocean (WTIO) and the Southeastern Tropical Indian Ocean (SETIO) indices in the Indian Ocean, which both have a clear signature in altimeter sea level anomalies.

Acknowledgements. The altimeter products were produced by Ssalto/Duacs and distributed by Aviso with support from CNES. Aviso staff is gratefully acknowledged for the services provided. The authors would like to express their thanks to B. Qiu and G. Larnicol for fruitful discussions. Helpful comments from the reviewers were appreciated.

Edited by: J. A. Johannessen

\section{References}

Barber, R. T and Chavez, F. P.: Biological Consequences of El Niño, Science, 222, 1203-1210, 1983

Brachet, S.: Variabilité mésoéchelle océanique, comparaison altimétrie/modèle, PhD Thesis, UPS-Toulouse III, 2005.

Borzelli, G. L. E., Gačić, M., Cardin, V., and Civitarese, G.: Eastern Mediterranean transient and reversal of the Ionian Sea circulation, Geophys. Res. Lett., 36, L15108, doi:10.1029/2009GL039261, 2009.

Civitarese, G., Gačić, M., Lipizer, M., and Eusebi Borzelli, G. L.: On the impact of the Bimodal Oscillating System (BiOS) on the biogeochemistry and biology of the Adriatic and Ionian Seas (Eastern Mediterranean), Biogeosciences, 7, 3987-3997, doi:10.5194/bg-7-3987-2010, 2010.

Criado-Aldeanueva, F., Del Río Vera, J., and García-Lafuente, J.: Steric and mass-induced Mediterranean sea level trends from 14 years of altimetry data, Global Planet. Change, 60, 563-575, doi:10.1016/j.gloplacha.2007.07.003, 2008.

Curry, R. G. and McCartney, M. S.: Ocean gyre circulation changes associated with the North Atlantic oscillation, J. Phys. Oceanogr., 31, 3374-3400, 2001.

Dibarboure, D., Pujol, M.-I., Briol, F., Le Traon, P.-Y., Larnicol, G., Picot, N., Mertz, F., and Ablain, M.: Jason-2 in DUACS: Updated System Description, First Tandem Results and Impact on Processing and Products, Mar. Geod., 34, 214-241, EEA, The 2010 State of the Environment, doi:10.2800/5862, 2011.

Ducet, N., Le Traon, P.-Y., and Reverdin, G.: Global high-resolution mapping of ocean circulation from TOPEX/Poseidon and ERS-1 and -2, J. Geophys. Res., 105, 19477-19498, 2000.

Enfield, D. B., Mestas, A. M., Mayer, D. A., and Cid-Serrano, L.: How ubiquitous is the dipole relationship in tropical Atlantic sea surface temperatures?, J. Geophys. Res., 104, 7841-7848, 1999

Gačić, M., Civitarese, G., Borzelli, G. L. E., Kovačević, V., Poulain, P.-M., Theocharis, A., Menna, M., Catucci, A., and Zarokanellos, N.: On the relationship between the decadal oscillations of the northern Ionian Sea and the salinity distributions in the eastern Mediterranean, J. Geophys. Res., 116, C12002, doi:10.1029/2011JC007280, 2011.

Gerin, R., Poulain, P.-M., Taupier-Letage, I., Millot, C., Ben Ismail, S., and Sammari, C.: Surface circulation in the Eastern Mediterranean using drifters (2005-2007), Ocean Sci., 5, 559574, doi:10.5194/os-5-559-2009, 2009.
Hamad, N., Millot, C., and Taupier-Letage, I.: A new hypothesis about the surface circulation in the eastern basin of the Mediterranean sea, Prog. Oceanogr,. 287-298, doi:10.1016/j.pocean.2005.04.002, 2005.

Kagimoto, T., Miyazawa, Y., Guo, X., and Kawajiri, H.: High resolution Kuroshio forecast system: Description and its applications, in: High Resolution Numerical Modelling of the Atmosphere and Ocean, edited by: Hamilton, K. and Ohfuchi, W., Springer New York, 209-239, 2008.

Kramer, W., Dijkstra, H. A., Pierini, S., and van Leeuwen, P. J.: Measuring the impact of observations on the predictability of the Kuroshio Extension in a shallow-water model, J. Phys. Oceanogr., 42, 3-17, ISSN 0022-3670, 2011.

McPhaden, M. J.: Genesis and evolution of the 1997-1998 El Niño, Science, 283, 950-954, 1999.

McPhaden, M. J.: Evolution of the 2002/03 El Niño:, B. Am. Meteorol. Soc., 85, 677-695, doi:10.1175/BAMS-85-5-677, 2004.

Meyssignac B. and Cazenave A.: Sea level : a review of present-day and recent-past sea level change and variability (invited review article), J. Geodyn., 58, 96-109, doi:10.1016/j.jog.2012.03.005, 2012.

Philander, S. G. H: El Niño, La Niña and the Southern Oscillation. Academic Press, San Diego, CA, 289 pp., 1990.

Pinardi, N., Korres, G., Lascaratos, A., Roussenov, V., and Stanev, E.: Numerical simulation of the interannual variability of the Mediterranean Sea upper ocean circulation, Geophys. Res. Lett., 24, 425-428, doi:10.1029/96GL03952, 1997.

Pujol, M.-I. and Larnicol, G.: Mediterranean Sea eddy kinetic energy variability from 11 years of altimetric data, J. Marine Syst., 58, 121-142, doi:10.1016/j.jmarsys.2005.07.005, 2005.

Qiu, B.: The Kuroshio extension system: Its large-scale variability and role in the midlatitude ocean-atmosphere interaction, J. Phys. Oceanogr., 58, 57-75, 2002.

Qiu, B.: Kuroshio Extension variability and forcing of the Pacific decadal oscillations: Responses and potential feedback, J. Phys. Oceanogr., 33, 2465-2482, 2003.

Qiu, B. and Chen, S.: Variability of the Kuroshio Extension Jet, Recirculation Gyre, and Mesoscale Eddies on Decadal Time Scales, J. Phys. Oceanogr., 35, 2090-2103, 2005.

Qiu, B. and Lukas, R.: Seasonal and interannual variability of the North Equatorial Current, the Mindanao Current and the Kuroshio along the Pacific western boundary, J. Geophys. Res., 101, 12315-12330, 1996.

Rasmusson, E. M. and Wallace, J. M.: Meteorological aspects of El Niño/Southern Oscillation, Science, 222, 1195-1202, 1983.

Reynolds, R. W., Rayner, N. A., Smith, T. M., Stokes, D. C., and Wang, W.: An improved in situ and satellite SST analysis for climate, J. Climate, 15, 1609-1625, 2002.

Rio, M.-H., Poulain, P.-M., Pascal, A., Mauri, E., Larnicol, G., and Santoleri, R.: A mean dynamic topography of the Mediterranean Sea computer from altimeter data, in situ measurements and a general circulation model, J. Marine Sys., 65, 484-508, 2007.

Rio, M.-H., Guinehut, S., and Larnicol, G.: The New CNES-CLS09 global Mean Dynamic Topography computed from the combination of GRACE data, altimetry and in-situ measurements, J. Geophys. Res., 113, C07018, doi:10.1029/2010JC006505, 2011.

Robinson, A. R., Golnaraghi, M., Leslie, W. G., Artegiani, A., Hecht, A., Lazzoni, E., Michelato, A., Sansone, E., Theocharis, A., and Ünlüata, Ü.: The eastern Mediterranean general circula- 
tion: features, structure and variability, Dynam. Atmos. Oceans, 15, 215-240, doi:10.1016/0377-0265(91)90021-7, 1991.

Roether, W., Klein, B., Manca, B. B., Theocharis, A., and Kioroglou, S.: Transient eastern Mediterranean deep waters in response to the massive dense-water output of the Aegean Sea in the 1990's, Prog. Oceanogr., 74, 540-571, doi:10.1016/j.pocean.2007.03.001, 2007.

Saji, N. H, Goswami, B. N., Vinayachandran, P. N., and Yamagata, T.: A dipole mode in the tropical Indian Ocean, Nature, 401, 360363, 1999.
Smith, T. M. and Reynolds, R. W.: Improved Extended Reconstruction of SST (1854-1997), J. Climate, 17, 2466-2477, 2004.

SSALTO/DUACS user handbook: http://www.aviso.oceanobs.com/ fileadmin/documents/data/tools/hdbk_duacs.pdf, 2011.

Trenberth, K. E. and Stepaniak, D. P.: Indices of El Niño evolution, J. Climate, 14, 1697-1701, 2001

Vigo, M. I., Sánchez-Reales, J. M., Trottini, M., Chao, B. F.: Mediterranean Sea level variations: Analysis of the satellite altimetric data, 1992-2008, J. Geodyn. 52, 271-278, doi:10.1016/j.jog.2011.02.002, 2011. 